\title{
Examining the Dimensionality of Trust in the Inpatient Setting: Exploratory and Confirmatory Factor Analysis
}

\author{
Megan E. Gregory, PhD ${ }^{1,2}$ (1), Kyi Phyu Nyein, PhD², Seth Scarborough, MAS', \\ Timothy R. Huerta, PhD, MS $1,2,3$, and Ann Scheck McAlearney, SCD, MS
}

\begin{abstract}
'Department of Biomedical Informatics, College of Medicine, The Ohio State University College of Medicine, Columbus, OH, USA; ${ }^{2}$ The Center for the Advancement of Team Science, Analytics, and Systems Thinking in Health Services and Implementation Science Research (CATALYST), The Ohio State University College of Medicine, Columbus, OH, USA; ${ }^{3}$ Department of Family and Community Medicine, College of Medicine, The Ohio State University College of Medicine, Columbus, OH, USA.
\end{abstract}

\begin{abstract}
BACKGROUND: Trust in healthcare providers is associated with important outcomes, but has primarily been assessed in the outpatient setting. It is largely unknown how hospitalized patients conceptualize trust in their providers.
\end{abstract}

OBJECTIVE: To examine the dimensionality of a measure of trust in the inpatient setting.

DESIGN: Exploratory factor analysis (EFA) and confirmatory factor analysis (CFA).

PARTICIPANTS: Hospitalized patients $(N=1756 ; 76 \%$ response rate) across six hospitals in the midwestern USA. The sample was randomly split such that approximately one half was used in the EFA, and the other half in the CFA.

MAIN MEASURES: The Trust in Physician Scale, adapted for inpatient care.

KEY RESULTS: Based on the Kaiser-Guttman criterion and parallel analysis, EFAs were inconclusive, indicating that trust may be comprised of either one or two factors in this sample. In follow-up CFAs, a 2-factor model fit best based on a chi-squared difference test $\left(\Delta \chi^{2}=151.48(1), p\right.$ $<.001)$ and a Comparative Fit Index (CFI) difference test (CFI difference $=$.03). The overall fit for the 2-factor CFA model was good $\left(\chi^{2}=293.56, \mathrm{df}=43, p<.01 ; \mathrm{CFI}=.95\right.$; RMSEA $=.081$ [90\% confidence interval = .072-.090]; TLI $=.93 ; \mathrm{SRMR}=.04)$. Items loaded onto two factors related to cognitive (i.e., whether patients view providers as competent) and affective (i.e., whether patients view that providers care for them) dimensions of trust.

CONCLUSIONS: While measures of trust in the outpatient setting have been validated as unidimensional, in the inpatient setting, trust appears to be composed of two factors: cognitive and affective trust. This provides initial evidence that inpatient providers may need to work to ensure patients see them as both competent and caring in order to gain their trust.

KEY WORDS: trust; trust in physician scale; psychometrics.

J Gen Intern Med 37(5):1108-14

DOI: $10.1007 /$ s11606-021-06928-w

(C) Society of General Internal Medicine 2021

Prior Presentations $N / A$

Received January 22, 2021

Accepted May 11, 2021

Published online June 2, 2021

\section{INTRODUCTION}

Trust between patients and healthcare professionals is critical to clinical practice to achieve positive outcomes for patients. A recent meta-analysis found that patients' trust in healthcare professionals - defined as a psychological state that is characterized by a trustor (i.e., patient) being vulnerable and having positive expectations about the trustee's (i.e., provider) intentions and behaviors ${ }^{1}$ - has been shown to improve healthrelated behaviors, experiences, and outcomes. ${ }^{2}$ More specifically, trust has been associated with improved treatment adherence, ${ }^{3}$ patient satisfaction, ${ }^{2}$ and quality of life. ${ }^{2}$ Trust is also a major factor influencing patient satisfaction with the inpatient environment. ${ }^{4}$ Low trust can lead to patients withholding medical information, ${ }^{5}$ and distrust has been associated with some patients refusing medical recommendations. ${ }^{6}$ Further, there are disparities in trust between minority and nonminority patients. ${ }^{7-9}$ Among minority patients as compared to White patients, mistrust has been associated with a lower likelihood of engaging in advance care planning or discussing end-of-life matters, ${ }^{10}$ and can contribute to lower medication adherence. $^{7}$ In the context of the coronavirus disease 2019 (COVID-19) pandemic, external factors have also been shown to impact some patients' trust in their physicians around information provided such as the benefits of vaccines, ${ }^{11}$ potentially eroding patient-provider relationships and/or contributing to suboptimal patient outcomes.

While critical, improving trust first requires an understanding of how patients think about trust, i.e., the dimensionality of trust. ${ }^{12-14}$ For instance, trust may be a unidimensional construct, such as patients globally trusting their doctors. ${ }^{13}$ Or, it is possible for trust to be multidimensional, with trust high in some areas - such as patients believing doctors are competent, and simultaneously low in other areas - such as patients not believing doctors have their best interests in mind. ${ }^{15,16}$ Most of the work examining trust has occurred in the outpatient setting. These studies have found that trust is unidimensional, such that patients view trust as a single trait, considering trust overall and not making distinctions among different areas in which healthcare professionals can or cannot be trusted. ${ }^{13}$ However, given factors specific to the inpatient setting, there may be reason to call into question whether the prevailing 
model for measuring trust in healthcare professionals holds as a unidimensional construct or whether it might be a multidimensional model. ${ }^{13,14,17}$

In the hospital context, patients are typically much more dependent upon healthcare professionals (e.g., medications, toileting, ambulation $)^{18}$ compared to outpatient settings, and thus may seek stronger interpersonal bonds. Further, shared decision-making differs in inpatient and outpatient settings in three major ways that likely impact trust: First, hospitalized patients often must make swift decisions about care (e.g., surgeries, procedures) which may impact decision-making compared to the outpatient setting where decisions can typically be made more deliberately. Second, hospitalized patients are often much sicker than outpatients, which may impact decision-making (e.g., patients have less capacity to make informed decisions and require more reliance on - and trust in - providers' expertise). ${ }^{19}$ Third, the unfamiliar and confusing environment of the hospital setting can make it challenging for patients to make decisions. This may be especially difficult for patients who have less experience in this setting. ${ }^{18}$

\section{Contributions of the Current Study}

The goal of this study is to examine trust and its dimensionality in a sample of hospitalized patients. Findings can serve as a step to informing interventions to improve inpatient trust. To be effective, interventions for improving trust must be related to the way that patients think about trust in their healthcare professionals. For example, if patients distinguish between trust in providers' skills and their honesty, it is possible that a patient might not consent to a procedure because while they trust that the provider is skilled in the procedure and would do a good job, they feel that the provider is trying to sell them on something that is not actually needed. Being able to understand not only whether - but how - patients trust their hospital team is crucial to informing efforts to improve trust and, ultimately, outcomes. Notably, while trust can be bidirection$\mathrm{al}$, trust in healthcare is much less reciprocal compared to other relationships due to the vulnerability that patients have toward providers. ${ }^{13}$ Thus, the current study focuses on patients' trust in healthcare professionals as a unidirectional relationship.

\section{METHOD}

This study was part of an IRB-approved larger study examining the use of patient portals in the inpatient setting. Using survey data collected in this study, we conducted exploratory factor analysis (EFA) and confirmatory factor analysis (CFA) of a trust measure that patients completed. EFA provides information about the dimensionality of a construct, using only the data itself, and without imposing the researcher's pre-determined structure onto the data. A follow-up CFA allows for testing the fit of this model in another group of participants and provides evidence of validity for the findings. Together, these analyses provide insight into how many dimensions a construct has, and what those dimensions are, and indicate how participants think about and make distinctions about a construct.

\section{Participants}

Participants were hospitalized patients. Patients were recruited during their inpatient stay if they were 18 years of age or older, were available in their room for recruitment (up to three attempts), and were capable of providing informed consent. Exclusion criteria included patients who were legally blind, had diminished decision-making capacity, could not speak or read English, and were involuntarily confined or detained. Participants provided informed consent and Health Insurance and Portability Accountability Act (HIPAA) authorization.

\section{Setting}

The study setting was a large, academic medical center comprised of six hospitals, including a safety net community hospital, and located in a large metropolitan area in the midwestern USA. Across the six included hospitals, there are over 1,200 patient beds.

\section{Procedures}

As part of hospital operations and the larger study, participants were provisioned tablets to provide access to some features of MyChart® Bedside (Epic Systems; Verona, WI), an inpatient portal allowing patients to do activities electronically such as receive education on their conditions and order meals. Tablets were provisioned after patient admission, typically no sooner than $6 \mathrm{~h}$ from admission, and up to 10 days or longer after admission. Research staff recruited eligible patients both on weekdays and on weekends. A survey was then activated on the portal and was available throughout their inpatient stay. This study took place from July 2017 to September 2018.

\section{Measures}

Trust in Healthcare Professionals. We adapted the Trust in Physician scale, ${ }^{12}$ which is an 11-item, validated, unidimensional measure of trust. Given the inpatient context, the scale was modified such that the targets of trust in the current study were many types of healthcare professionals (e.g., "If my doctor, nurse, or other healthcare professional tells me something is so, then it must be true"), rather than the original items which were designed for the outpatient setting and focused solely on relationships with physicians (e.g., "If my doctor tells me something is so, then it must be true"). Items were scaled on a 5-point Likert scale ( $1=$ strongly disagree, $5=$ strongly agree).

Demographics. Race, ethnicity, age, gender, and Charlson score were pulled from patient records. Participants were asked their marital status, level of education, employment 
status, household income, and healthcare coverage status in the enrollment survey.

\section{Analyses}

Analyses were conducted in Stata (v. 16). ${ }^{20}$ Missing data were dropped listwise. Items were reverse coded when necessary. The sample was randomly split in half by generating uniformly distributed random values over the interval 0 to 1 using Stata's runiform command, assigning a value to each observation and splitting at the midpoint of these values. Randomization was performed on patients with a valid survey response. We conducted an EFA on one half, followed by a CFA on the second half.

$\boldsymbol{E F A}$. EFA was performed on the data using principal axis factoring and oblique promax rotation, which accounts for correlation between factors. To determine the number of dimensions, we examined eigenvalues (following the KaiserGuttman criterion, retaining factors with eigenvalues $>1.0),{ }^{21}$ parallel analysis diagrams, ${ }^{22}$ and factor loadings (retaining items that loaded $\geq .30$ ).

$\boldsymbol{C F A}$. CFA using maximum likelihood estimation was subsequently conducted. We examined fit indices (chisquared, Comparative Fit Index [CFI], root mean square error of approximation [RMSEA], Tucker Lewis Index [TLI], and standardized root mean squared residual [SRMR]) to assess model fit in accordance with commonly used fit index cutoff criteria ${ }^{23}$ and reviewed item loadings to ensure that all items loaded $\geq .30$.

Additional Scale Properties. Internal consistency reliability was computed using Cronbach's alpha.

\section{RESULTS}

\section{Demographics}

Overall, 2,310 patients met inclusion criteria for the current study. One thousand seven hundred fifty-six patients completed the full list of trust items in the enrollment survey (response rate $=76.0 \%)$. Participants were largely white $(N=1,417$, $80.69 \%)$, and non-Hispanic $(N=1,556,88.61 \%)$. Participants were $39.64 \%(N=696)$ male and $60.36 \%(N=1,060)$ female, and aged between 18 and 91 years $(M=45.79, S D=14.69)$. Most $(62.87 \%)$ had at least some college education. The average Charlson score was 1.63. Patients were most frequently married, were employed, unemployed, and retired, tended to have incomes below $\$ 50,000$, and most had health insurance. The median length of stay was 6 days and the mean was 8.24 days $(\mathrm{SD}=8.30)$. See Table 1 for more detailed demographics.
Table 1 Demographics $(N=1,756)$

\begin{tabular}{|c|c|c|}
\hline Variable & Level of variable & $\begin{array}{l}\text { Statistics } \\
\text { (n, \% or M, SD) }\end{array}$ \\
\hline \multirow[t]{8}{*}{ Race } & White & $1417(80.69 \%)$ \\
\hline & Black & $275(15.66 \%)$ \\
\hline & Asian & $7(0.40 \%)$ \\
\hline & American Indian/Alaska & $8(0.46 \%)$ \\
\hline & Native & \\
\hline & More than one race & $16(0.91 \%)$ \\
\hline & Other or unknown to patient & $28(1.59 \%)$ \\
\hline & (Missing) & $5(0.28 \%)$ \\
\hline \multirow[t]{2}{*}{ Gender } & Female & $1,060(60.36 \%)$ \\
\hline & Male & $696(39.64 \%)$ \\
\hline \multirow[t]{5}{*}{ Age } & $18-34$ & $471(26.82 \%)$ \\
\hline & $35-49$ & $542(30.87 \%)$ \\
\hline & $50-64$ & $551(31.38 \%)$ \\
\hline & $65-74$ & $160(9.11 \%)$ \\
\hline & $75+$ & $32(1.82 \%)$ \\
\hline \multirow[t]{7}{*}{ Household income } & $\$ 0-\$ 19,999$ & $512(29.16 \%)$ \\
\hline & $\$ 20,000-\$ 34,999$ & $220(12.53 \%)$ \\
\hline & $\$ 35,000-\$ 49,999$ & $161(9.17 \%)$ \\
\hline & $\$ 50,000-\$ 74,999$ & $228(12.98 \%)$ \\
\hline & $\$ 75,000-\$ 99,999$ & $145(8.26 \%)$ \\
\hline & $\$ 100,000$ or more & $242(13.78 \%)$ \\
\hline & (Missing) & $248(14.12 \%)$ \\
\hline Charlson score & Mean (SD) & $1.63(2.08)$ \\
\hline \multirow{5}{*}{ Marital status } & Married or living as married & $835(47.55 \%)$ \\
\hline & Widowed & $237(13.50 \%)$ \\
\hline & Divorced or separated & $117(6.66 \%)$ \\
\hline & Single, never married & $415(23.63 \%)$ \\
\hline & (Missing) & $152(8.66 \%)$ \\
\hline \multirow{4}{*}{$\begin{array}{l}\text { Employment } \\
\text { status }\end{array}$} & Employed & $744(42.37 \%)$ \\
\hline & Unemployed & $671(38.21 \%)$ \\
\hline & Retired & $187(10.65 \%)$ \\
\hline & (Missing) & $154(8.77 \%)$ \\
\hline \multirow[t]{6}{*}{ Education } & Less than high school & $83(4.73 \%)$ \\
\hline & High school & $418(23.80 \%)$ \\
\hline & Some college & $481(27.39 \%)$ \\
\hline & College graduate & $411(23.41 \%)$ \\
\hline & Graduate or beyond & $212(12.07 \%)$ \\
\hline & (Missing) & $151(8.60 \%)$ \\
\hline Healthcare & Yes & $1,455(82.86 \%)$ \\
\hline \multirow[t]{2}{*}{ coverage } & No & $135(7.69 \%)$ \\
\hline & (Missing) & $166(9.45 \%)$ \\
\hline Length of Stay & \multicolumn{2}{|c|}{$\mathrm{Mdn}=6$ days; $\mathrm{M}=8.24$ days $(\mathrm{SD}=8.30)$} \\
\hline
\end{tabular}

$M$ mean, SD standard deviation, Mdn median

We compared our sample to the overall sample of hospitalized patients during the study period on the basis of gender, race, and age. Gender did not differ significantly between our sample and overall hospitalized patients. However, race differed significantly $\left(X^{2}=\right.$ $1,148.60, p<.0001)$, particularly in the proportion of patients who were listed as other/multiple races who made up a larger proportion of the study population as compared to the hospital population $(2.51 \%$ vs $0.04 \%)$. There was also a smaller proportion of Asian patients in our study $(0.40 \%$ vs $1.40 \%)$, and a smaller proportion of patients who had missing data on race in our study $(0.28 \%$ vs. $5.37 \%)$. Age also differed significantly $\left(X^{2}=\right.$ $412.55, p<.0001)$, such that our sample contained a greater proportion of younger patients and a smaller proportion of older patients as compared to overall hospitalized patients. 


\section{Exploratory Factor Analysis}

An EFA was conducted on subsample $1(N=869)$ without restricting the number of factors. The KMO was .93. Five factors were retained, and parallel analysis suggested a multifactor solution. While the parallel analysis indicated four factors were technically above the cutoff line, visual inspection of the plot strongly suggested a 2-factor solution was more appropriate (see Fig. 1). Yet, examination of eigenvalues (i.e., retaining factors with eigenvalues $>1$ ) suggested a 1factor solution (top two eigenvalues were 5.09 followed by 0.49). As a result, we subsequently re-ran the EFA twice, restricting the number of factors to one and two. In the 2factor model, the factors were correlated at .70. Table 2 provides rotated factor loadings for both the 1- and 2-factor models. All items loaded adequately ( $>.30)$ on factors; thus, all items were retained. Upon examination of the item loadings in the 2-factor model, a factor structure seemingly aligned with Webber's ${ }^{16}$ conceptualization of affective and cognitive trust emerged, with items about trusting the reliability and competence of healthcare professionals generally loading onto factor 1 , and items more related to interpersonal care and concern loading onto factor 2 . One exception is item 3 , which loaded almost equally onto both factors; upon examination, the underlying concept of this item (distrusting a healthcare professional's knowledge and desiring a second opinion) was conceptually more aligned with cognitive trust. We thus assigned it to the cognitive dimension for the subsequent CFA.

\section{Confirmatory Factor Analysis}

We conducted CFAs with a second subsample of 887 participants. Based on the results of the EFA, we tested both 1- and 2-factor CFA models. The 1-factor model (see Fig. 2) fit adequately $\left(\chi^{2}=445.04, \mathrm{df}=44, p<.01 ; \mathrm{CFI}=.92\right.$; RMSEA $=.101[90 \%$ confidence interval $=.093-.110] ;$ TLI $=.90$; SRMR $=.05$ ) and all items loaded strongly onto the general trust factor. The 2-factor model (see Fig. 3) fit well $\left(\chi^{2}=\right.$ 293.56, $\mathrm{df}=43, p<.01 ; \mathrm{CFI}=.95 ; \mathrm{RMSEA}=.081[90 \%$

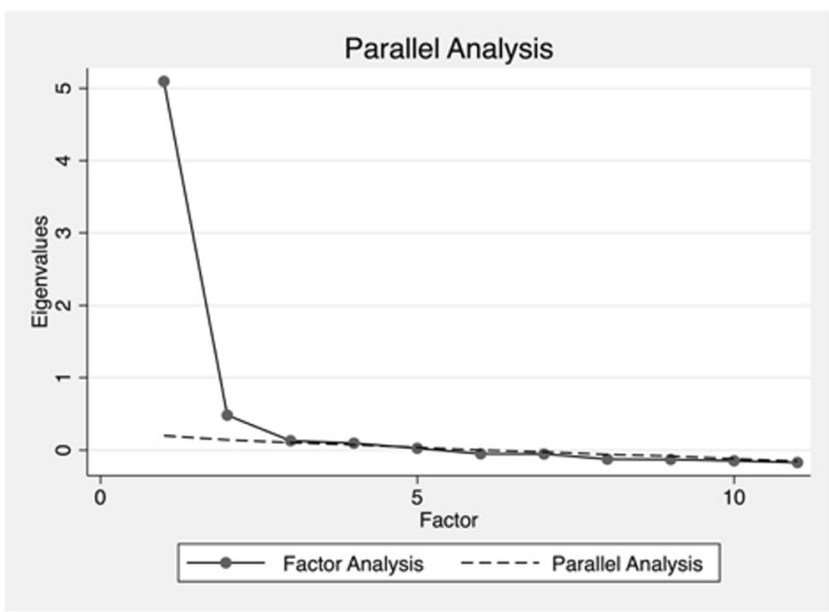

Figure 1 Parallel analysis results of inpatient trust in healthcare professionals EFA.
Table 2 EFA Rotated Factor Loadings (Pattern Matrix) for 1- and 2-Factor Models

\begin{tabular}{|c|c|c|c|}
\hline Item & $\begin{array}{l}\text { Factor } 1 \\
\text { (1-factor } \\
\text { model) }\end{array}$ & $\begin{array}{l}\text { Factor } 1 \\
\text { (2-factor } \\
\text { model) }\end{array}$ & $\begin{array}{l}\text { Factor } 2 \\
\text { (2-factor } \\
\text { model) }\end{array}$ \\
\hline $\begin{array}{l}\text { Item } 1 \text {. I trust my doctor, } \\
\text { nurse, or other healthcare } \\
\text { professional so much I } \\
\text { always try to follow his/ } \\
\text { her advice. }\end{array}$ & 0.73 & 0.56 & - \\
\hline $\begin{array}{l}\text { Item 2. If my doctor, } \\
\text { nurse, or other healthcare } \\
\text { professional tells me } \\
\text { something is so, then it } \\
\text { must be true. }\end{array}$ & 0.59 & 0.64 & - \\
\hline $\begin{array}{l}\text { Item 3. I sometimes } \\
\text { distrust my doctor, nurse, } \\
\text { or other healthcare } \\
\text { professional's opinions } \\
\text { and would like a second } \\
\text { one. (RC) }\end{array}$ & 0.69 & 0.38 & 0.37 \\
\hline $\begin{array}{l}\text { Item 4. I trust my doctor, } \\
\text { nurse, or other healthcare } \\
\text { professional's judgments } \\
\text { about my medical care. }\end{array}$ & 0.78 & 0.58 & - \\
\hline $\begin{array}{l}\text { Item 5. I feel my doctor, } \\
\text { nurse, or other healthcare } \\
\text { professional does not do } \\
\text { everything he/she should } \\
\text { about my medical care. } \\
\text { (RC) }\end{array}$ & 0.70 & - & 0.75 \\
\hline $\begin{array}{l}\text { Item 6. My doctor, nurse, } \\
\text { or other healthcare } \\
\text { professional is usually } \\
\text { considerate of my needs } \\
\text { and puts them first. }\end{array}$ & 0.73 & - & 0.63 \\
\hline $\begin{array}{l}\text { Item 7. I trust my doctor, } \\
\text { nurse, or other healthcare } \\
\text { professional to tell me if a } \\
\text { mistake was made about } \\
\text { my treatment. }\end{array}$ & 0.69 & 0.77 & - \\
\hline $\begin{array}{l}\text { Item } 8 \text {. I sometimes worry } \\
\text { that my doctor, nurse, or } \\
\text { other healthcare } \\
\text { professional may not keep } \\
\text { the information we } \\
\text { discuss totally private. } \\
\text { (RC) }\end{array}$ & 0.52 & - & 0.40 \\
\hline $\begin{array}{l}\text { Item 9. My doctor, nurse, } \\
\text { or other healthcare } \\
\text { professional is well } \\
\text { qualified to manage, } \\
\text { diagnose and treat, or } \\
\text { make an appropriate } \\
\text { referral for medical } \\
\text { problems like mine. }\end{array}$ & 0.65 & - & 0.46 \\
\hline $\begin{array}{l}\text { Item 10. I doubt that my } \\
\text { doctor, nurse, or other } \\
\text { healthcare professional } \\
\text { really cares about me as a } \\
\text { person. (RC) }\end{array}$ & 0.63 & - & 0.74 \\
\hline $\begin{array}{l}\text { Item } 11 \text {. I trust my doctor, } \\
\text { nurse, or other healthcare } \\
\text { professional to put my } \\
\text { medical needs above all } \\
\text { other considerations when } \\
\text { treating my medical } \\
\text { problems. }\end{array}$ & 0.75 & 0.76 & - \\
\hline
\end{tabular}

- represents absolute value loadings of $<.30 . R C$ reverse coded

confidence interval $=.072-.090] ; \mathrm{TLI}=.93 ; \mathrm{SRMR}=.04)$ and all items loaded strongly onto their assigned factor. While the 2-factor model appeared to have better fit, we conducted chisquare and CFI difference tests to confirm. The results of the 


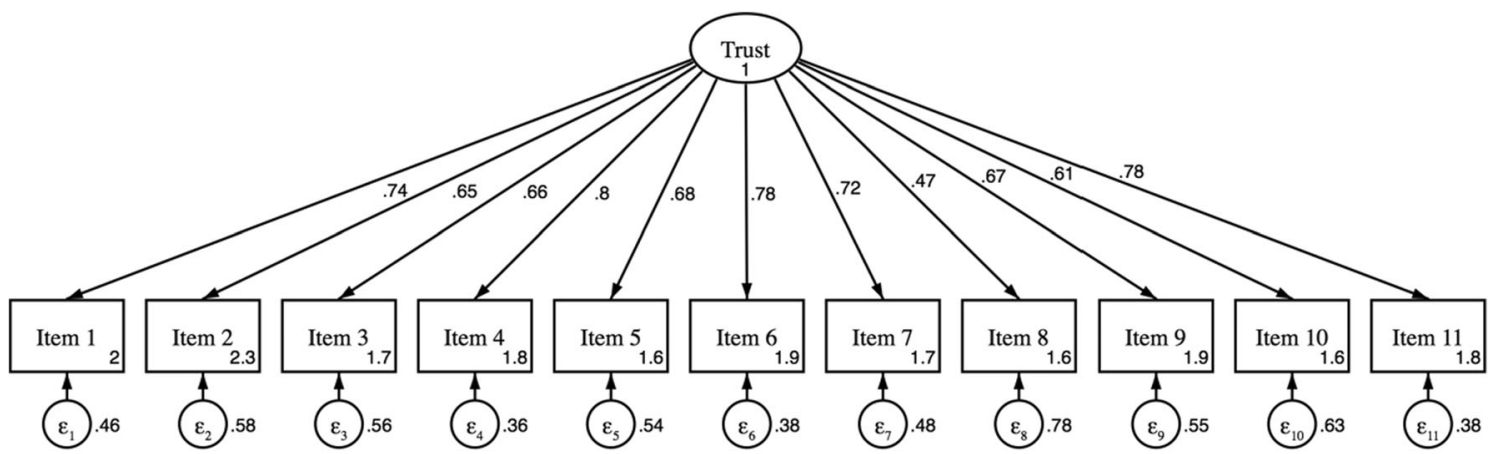

Figure 2 CFA 1-factor model of a unidimensional trust factor.

chi-square difference test $\left(\Delta \chi^{2}=151.48(1), p<.001\right)$ and the CFI difference test result of .03 indicated that the 2-factor model fit significantly better.

\section{Additional Scale Properties}

Cronbach's alpha for the scale was $\alpha=.90$ in the EFA subsample and $\alpha=.90$ in the CFA subsample.

\section{DISCUSSION}

Interestingly, our study shows that what we know about patients' trust in their healthcare professionals - and potentially, other interpersonal relationship dynamics between patients and their healthcare professionals largely based on research in the outpatient setting - may not apply to the inpatient setting. Despite the fact that the Trust in Physician scale was validated as a unidimensional measure of trust adapted from Anderson and Dedrick, ${ }^{12}$ and that prior work has suggested that trust seems to be unidimensional in context of healthcare, ${ }^{12,13}$ we found that trust in the inpatient setting using an adapted version of Anderson and Dedrick's ${ }^{12}$ scale was two-dimensional. Specifically, our results were consistent with theories that suggest trust is composed of both a cognitive dimension (a positive belief regarding the trustee's competence and ability) and an affective dimension (concerned with emotional bond between the trustor and trustee $\left.{ }^{16}\right)$. This is despite a median length of stay of only 6 days for our sample and the fact that hospitalized patients are often being cared for by healthcare professionals they do not know. However, prior work suggests that patients form trust impressions quickly, and trust is not strongly associated with how well patients know their providers. ${ }^{13}$ The conditions of the inpatient setting may facilitate development of more granular trust perceptions; furthermore, hospitalized patients may more closely scrutinize the providers with whom they did not choose nor knew in advance but must rely upon heavily, perhaps explaining why trust is multidimensional in this sample.

Notably, one prior study of Anderson and Dedrick's ${ }^{12}$ scale also found two dimensions of trust - albeit in the outpatient setting. Aloba and colleagues ${ }^{24}$ administered the scale to Nigerian psychiatric outpatients. The results of a principal components analysis suggested there were two factors seemingly related to doubt and trustworthiness; yet, the doubt factor was comprised entirely of items that were reverse scored, whereas the trustworthiness factor was comprised entirely of non-reverse scored items. Thus, it is possible that their results are simply a methodological artifact. Further, Cronbach's alpha of their scale was below .70 , providing additional evidence of methodological issues. Moreover, previous work has examined inpatients' trust in nurses, and found a similar

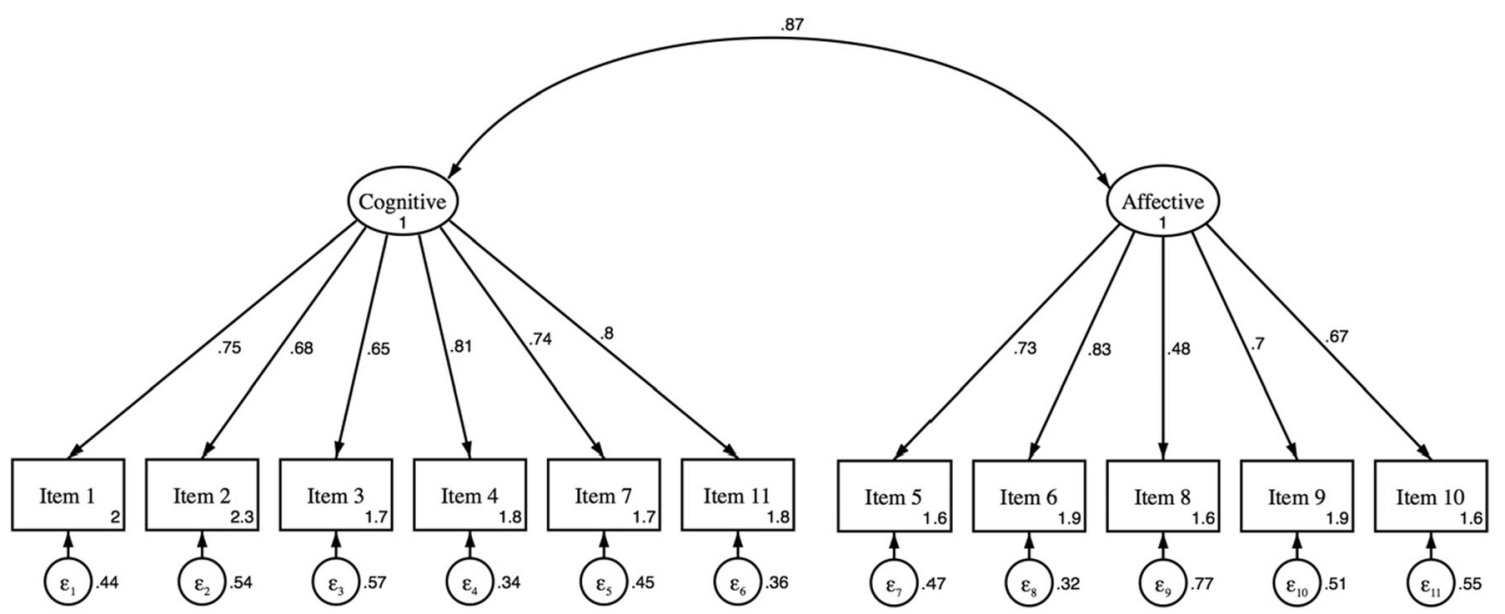

Figure 3 CFA 2-factor model of cognitive and affective trust. 
pattern of findings as the current study. Specifically, Ozaras and $\mathrm{Abaan}^{25}$ found that hospitalized patients considered both personal (e.g., being loving and respectful) and professional (e.g., doing tasks competently) characteristics when developing trust with nurses. These are similar to the concepts of affective and cognitive trust, and provide additional support for our findings. The current study supplements these findings by extending them to other types of healthcare professionals.

Our results provide important insights for healthcare delivery and future research on measures of patient trust and its dimensions as they indicate that healthcare professionals should foster both the cognitive trust and affective trust of their hospitalized patients (see Table 3 for evidence-based strategies). ${ }^{26-31}$ These findings also have important implications for hospitalized patients in the context of the COVID-19 pandemic. For instance, many patients are distrusting of the new COVID-19 vaccines. ${ }^{11,32}$ Healthcare professionals have also reported instances in which a hospitalized COVID-19positive patient has denied having the disease, ${ }^{33}$ despite their deteriorating condition. ${ }^{34}$ Healthcare professionals faced with these circumstances who seek to increase trust can benefit from the results of this study by considering that hospitalized patients may not only be forming judgments about trust based on professionals' competence and expertise, but also through perceptions that their healthcare professionals have their best interests in mind and care for them as a person.

\section{Limitations}

We adapted the Trust in Physician scale from Anderson and Dedrick. $^{12}$ Thus, we cannot disentangle effects due to the inpatient sample as compared to the modifications we made to the wording of items. As our adaptations were minor, we do not expect that these played a significant role in the differing

Table 3 Practices to Increase Cognitive and Affective Trust of Healthcare Professionals in the Inpatient Setting

\begin{tabular}{|c|c|}
\hline Dimension & Strategies \\
\hline $\begin{array}{l}\text { Cognitive } \\
\text { trust }\end{array}$ & $\begin{array}{l}\text { - Emphasize expertise and ability - introduce self and } \\
\text { describe credentials upon first visit }{ }^{26,31} \\
\text { - Tell patients they can ask questions }{ }^{30} \\
\text { - Show lab/test results and explain them } \\
\text { - Provide training for healthcare professionals to } \\
\text { increase their skills in this area }\end{array}$ \\
\hline $\begin{array}{l}\text { Affective } \\
\text { trust }\end{array}$ & $\begin{array}{l}\text { - Provide patients with emotional support }{ }^{26} \\
\text { - Ensure use of effective communication skills }{ }^{27,} 28 \\
\text { - Make an effort to relate to patients (e.g., discuss } \\
\text { mutual interests) } \\
\text { - Provide reassurance } \\
\text { - Ask patients about their preferences }{ }^{30} \\
\text { - Avoid judgmental language and behavior }{ }^{30} \\
\text { - Show the patient you respect them as a person } \\
\text { - Respect patients' time (e.g., return when you say you } \\
\text { will) } \\
\text { - Spend time during initial visit to establish rapport } \\
\text { (e.g., act like a guest) } \\
\text { - Provide training for healthcare professionals to } \\
\text { increase their skills in this area } \\
\text { - Develop job aids (e.g., pocket cards) with tools and } \\
\text { phrases for healthcare professionals to use to open up } \\
\text { an effective, trusting dialogue }\end{array}$ \\
\hline
\end{tabular}

factor structure, but future research should be conducted to confirm this. Additionally, we did not consider other dimensions or measures of trust and we were unable to identify the existence of potential other dimensions (e.g., Mechanic and Meyer $^{35}$; Thom and Campbell ${ }^{36}$ ). However, as none of these measures were developed specifically for hospitalized patients, future work should seek to fully develop a measure for trust in the inpatient setting.

Moreover, as the current study was conducted as part of a larger study within six hospitals, the extent to which the results generalize to other hospital systems is unknown. Further, the proportion of older adults in our study was relatively low compared to that of the overall hospital population. This was likely due in part to our exclusion criteria, and to older adults choosing not to use the tablet on which the survey was deployed during their stay. It would be interesting for future research to examine inpatient trust specifically in the older adult population, and potentially to compare this to trust in other age groups. Additionally, the current study aggregated patients of all races together to provide as robust of a sample size as possible for an initial exploration into the dimensionality of trust in the inpatient setting; thus, we did not investigate measurement equivalence between races. Our sample was composed of $80 \%$ White patients, and included only patients who spoke English; thus, future work is needed to validate our findings in more diverse samples. Lastly, it is unknown to what extent patients' trust of the different healthcare professionals with whom they interacted varied. Future research should explore how and why patients may differentially trust members of various professions, as well as of different individuals involved in their inpatient care.

Acknowledgements: The authors wish to thank current and former staff at CATALYST for their assistance with this project, as well as all the participants in this study. Conduct of this research was reviewed and approved by the Institutional Review Board of the authors.

Corresponding Author: Megan E. Gregory, PhD; The Center for the Advancement of Team Science, Analytics, and Systems Thinking in Health Services and Implementation Science Research (CATALYST), The Ohio State University College of Medicine, Columbus, OH, USA (e-mail: megan.gregory@osumc.edu).

Funding This research was supported by grants from the Agency for Healthcare Research and Quality (Grant \#RO1HSO2409 and Grant \#P3OHSO24379).

\section{Declarations:}

Conflict of Interest: The authors declare that they do not have a conflict of interest.

\section{REFERENCES}

1. Rousseau D, Sitkin SB, Burt RS, Camerer C. Not so different after all: A cross-discipline view of trust. Acad Manage Rev. 1998;23(3):393-404

2. Birkhäuer $\mathbf{J}$, Gaab $\mathbf{J}$, Kossowsky $\mathbf{J}$, et al. Trust in the health care professional and health outcome: A meta-analysis. PLOS One. 2017;12(2):e0170988. 
3. Thom D, Kravitz RL, Bell RA, Krupat E, Azari R. Patient trust in the physician: relationship to patient requests. Fam Pract. 2002;19(5):47683.

4. Shan L, Li Y, Ding D, et al. Patient satisfaction with hospital inpatient care: effects of trust, medical insurance and perceived quality of care. PLoS One. 2016;11(10):e0164366.

5. Walker D, Johnson T, Ford EW, Huerta TR. Trust me, I'm a doctor: examining changes in how privacy concerns affect patient withholding behavior. J Med Internet Res. 2017;19(1):e2.

6. Sharf BF, Stelljes LA, Gordon HS. A little bitty spot and I'm a big man': patients' perspectives on refusing diagnosis or treatment for lung cancer. Psychooncology. 2005; 14(8):636-46.

7. Haywood C, Lanzkron S, Bediako S, et al. Perceived discrimination, patient trust, and adherence to medical recommendations among persons with sickle cell disease. J Gen Intern Med. 2014;29(12):1657-62.

8. Fareed N, Swoboda CM, Jonnalagadda P, Walker DM, Huerta TR. Differences between races in health information seeking and trust over time: evidence from a cross-sectional, pooled analyses of HINTS data. Am J Health Promot. 2020; In Press.

9. Jacobs E, Mendenhall E, McAlearney AS, et al. An exploratory study of how trust in health care institutions varies across African American, Hispanic and white populations. Commun Med. 2011;8(1):89-98.

10. Bazargan M, Bazargan-Hejazi S. Disparities in palliative and hospice care and completion of advance care planning and directives among nonHispanic blacks: A scoping review of recent literature. Am J Hosp Palliat Care. 2020:1-31.

11. Fisher K, Bloomstone B, Walder J, Crawford S, Fouayzi H. Attitudes toward a potential SARS-CoV-2 vaccine: A survey of U.S. adults. Ann Intern Med. 2020;In Press:M20-3569.

12. Anderson L, Dedrick RF. Development of the Trust in Physician scale: a measure to assess interpersonal trust in patient-physician relationships. Psychol Rep. 1990;67:1091-100.

13. Hall M, Dugan E, Zheng B, Mishra AK. Trust in physicians and medical institutions: What is it, can it be measured, and does it matter? Milbank Q. 2001;79(4):613-39.

14. Bova C, Route PS, Fennie K, Ettinger W, Manchester GW, Weinstein B. Measuring patient-provider trust in a primary care population: Refinement of the health care relationship trust scale. Res Nurs Health. 2012;35(4):397-408

15. Colquitt J, Scott BA, LePine JA. Trust, trustworthiness, and trust propensity: A meta-analysis test of their unique relationships with risktaking and job performance. J Appl Psychol. 2007;92(4):909-27.

16. Webber S. Development of cognitive and affective trust in teams: A longitudinal study. Small Group Res. 2008;39(6):746-69.

17. Pearson S, Raeke LH. Patients' trust in physicians: many theories, few measures, and little data. J Gen Intern Med. 2000;15(7):509-13.

18. Kalaitzidis E. Patients' decision-making experiences in the acute healthcare setting - a case study. Scand J Caring Sci. 2016;30(1):83-90.

19. Lepping P, Stanly T, Turner J. Systematic review on the prevalence of lack of capacity in medical and psychiatric settings. Clin Med. 2015;15:337-43.
20. StataCorp. Stata Statistical Software: Release 16. College Station, TX: StataCorp LLC; 2019.

21. Nunnally J, Bernstein I. Psychometric Theory. 3rd ed. New York: McGraw-Hill; 1994.

22. Ender P. fapara: Factor analysis parallel analysis. UCLA: Statistical Consulting Group; 2010.

23. Hu L, Bentler PM. Cutoff criteria for fit indexes in covariance structure analysis: Conventional criteria versus new alternatives. Struct Equ Modeling. 1999;6(1):1-55.

24. Aloba O, Mapayi B, Akinsulore S, Ukpong D, Fatoye O. Trust in Physician Scale: factor structure, reliability, validity and correlates of trust in a sample of Nigerian psychiatric outpatients. Asian J Psychiatr. 2014;11:20-7.

25. Ozaras G, Abaan S. Investigation of the trust status of the nurse-patient relationship Nurs Ethics. 2018;25(5):628-39.

26. Ommen O, Thuem S, Pfaff $\mathbf{H}$, Janssen C. The relationship between social support, shared decision-making and patient's trust in doctors: a cross-sectional survey of 2,197 inpatients using the Cologne Patient Questionnaire. Int J Public Health. 2011;56(3):319-27.

27. McAlearney A, Oliveri JM, Post DM, et al. Trust and distrust among Appalachian women regarding cervical cancer screening: a qualitative study. Patient Educ Couns. 2012;86(1):120-6.

28. Hamelin N, Nikolis A, Armano J, Harris PG, Brutus JP. Evaluation of factors influencing confidence and trust in the patient-physician relationship: A survey of patient in a hand clinic. Chir Main. 2012;31(2):8390.

29. Moriates C, Baig M. Building trust through punk rock. Ann Intern Med. 2019;171:139-40.

30. Dang B, Westbrook R, Njue $\mathbf{S}$, Giordano T. Building trust and rapport early in the new doctor-patient relationship: a longitudinal qualitative study. BMC Med Educ. 2017;17(1):1-10.

31. Leslie J, Lonneman W. Promoting trust in the registered nurse-patient relationship. Home Healthcare Now. 2016;34(1):38-42.

32. Kittleson M. Trust in the time of COVID-19. Am J Med. 2020;133(12):1370-1.

33. Sun $\mathbf{N}$, Wei $\mathbf{L}$, Wang $\mathbf{H}$, et al. Qualitative study of the psychological experience of COVID-19 patients during hospitalization. J Affect Disord. 2021;278:15-22.

34. Basen R. COVID patients' crackpot theories take toll on healthcare workers - their last dying words are 'this can't be happening, this isn't real'. Medpage Today. 2020. https://www.medpagetoday.com/ infectiousdisease/covid 19/89796.

35. Mechanic D, Meyer S. Concepts of trust among patients with serious illness. Soc Sci Med. 2000;51(5):657-68.

36. Thom D, Campbell B. Patient-physician trust: an exploratory study. J Fam Pract. 1997;44(2):169-76.

Publisher's Note: Springer Nature remains neutral with regard to jurisdictional claims in published maps and institutional affiliations. 